\title{
Bilateral mandibular premolars with tooth shape deviation: a rare dental anomaly
}

\author{
Costa, GBF. * Ramos-Perez, FMM., Castro, JFL. and Perez, DEC. \\ Department of Clinical and Preventive Dentistry, School of Dentistry, Federal University of Pernambuco - UFPE, \\ Av. Prof. Moraes Rego, 1235, Cidade Universitária, CEP 50670-901, Recife, PE, Brazil \\ *E-mail: gillienecosta@hotmail.com
}

\begin{abstract}
The tooth shape deviations are rare dental anomaly described in premolars, characterized by to show simultaneously an increased mesio-distal dimension and decreased bucco-lingual dimension when compared with other normal teeth. The presence of such teeth with variation in size may be related to malocclusions, since there is a reduction in circumference of the dental arch. This report describes a rare case of bilateral tooth shape deviations in the two mandibular first premolars and discusses the prevalence of this condition and the eventual clinical consequences associated with this dental anomaly.
\end{abstract}

Keywords: anatomy, dental anomalies, malocclusion, morphology, teeth.

\section{Introduction}

During the development of the maxillo-mandibular complex structures, the teeth are susceptible to disturbances caused by environmental, idiopathic or hereditary causes. These disturbances may result in changes in development that may cause esthetic and functional damage (GARIB, ZANELLA and PECK, 2005). The majority of these changes occur in the third molars, maxillary lateral incisors and mandibular premolars. Among these developmental disturbances are dental anomalies of size, which include microdontia, macrodontia and tooth shape deviation (DUGMORE, 2001; GARIB and PECK, 2006; CHATE, 2012).

Macrodontia results from disturbance in the morphodifferentiation stage of tooth germ development, and may be characterized by a tooth with increase in the size of all its dimensions, when compared with other teeth considered normal (FUENTES and BORIE, 2011). It presents low prevalence and the maxillary third molars are the most affected teeth (DUGMORE, 2001). The mandibular premolars may also be affected, and in this case macrodontia is also denominated molarization (GARIB and PECK, 2006; CANUT and ARIAS, 1999).

Tooth shape deviation consists of a rare anatomic variation described in the mandibular premolars. Teeth with this alteration simultaneously present an increased mesio-distal and diminished bucco-lingual dimension when compared with normal teeth (CHATE, 2012). This dental developmental anomaly may lead to alteration in the eruption of other permanent teeth, changing the perimeter of the arch, in addition to causing disturbances in occlusion (NAGPAL, PAI and SHARMA, 2009).

Recent research has found a prevalence of $0.56 \%$ of this anomaly in the British population, with $16.07 \%$ of affected individuals presenting bilateral occurrence of mandibular first premolars (CHATE, 2012). Because of the rarity and clinical consequences associated with this dental anomaly, the report of additional cases is important. Therefore, the aim of this report is to describe a case of bilateral tooth shape deviations in mandibular first premolars, emphasizing their clinical characteristics and clinical consequences, particularly the occurrence of dental malocclusion.

\section{Case report}

A 19-year-old white man, who had not deleterious or paradental habits, consulted the dentist, complaining of misaligned teeth and requesting orthodontic evaluation. After detailed anamnesis, it was verified that the patient presented no systemic alteration or pre-existent disease.

The intraoral examination revealed the absence of space in the maxillary arch for the correct positioning of the left maxillary first premolar (palatal-version), and in the mandibular arch for the complete eruption of the left mandibular canine (retention). In addition, there was the presence of tooth crowding in the two arches, which favored the retention of food and made it difficult to perform correct oral hygiene. The patient presented Angle's Class III malocclusion on both sides (right and left). Complementary exams were requested (panoramic radiography, plaster study models and intraoral photographs), in order to obtain the correct diagnosis of the patient.

Panoramic radiography indicated that the density and trabeculate of the basal bone were normal, and the alveolar bone crest height was conserved. After detailed analysis of the intraoral photographs and the plaster study models, it was observed that the left mandibular first premolar and right mandibular first premolar presented tooth shape deviation, while the other teeth were normal in size and shape (Figure 1). Both mandibular first premolars presented a crown with an irregular shape, larger mesio-distal measurement $(11 \mathrm{~mm})$ and discreetly smaller bucco-lingual measurement $(8 \mathrm{~mm})$ than the conventional premolars (Figure 2). Although they presented altered shape, these teeth were shown to be whole, with absence of caries or periodontal disease, and responded positively to a cold pulp vitality tests. There was no history of trauma or discomfort associated with these teeth, or similar cases in family members. 
Additionally, the presence of the tooth shape deviations was associated with the retention of the left mandibular canine and rotation of the right mandibular canine, the latter probably due to the disturbance in the shape of the adjacent first premolar. In view of the condition of malocclusion, the patient was referred for orthodontic treatment.
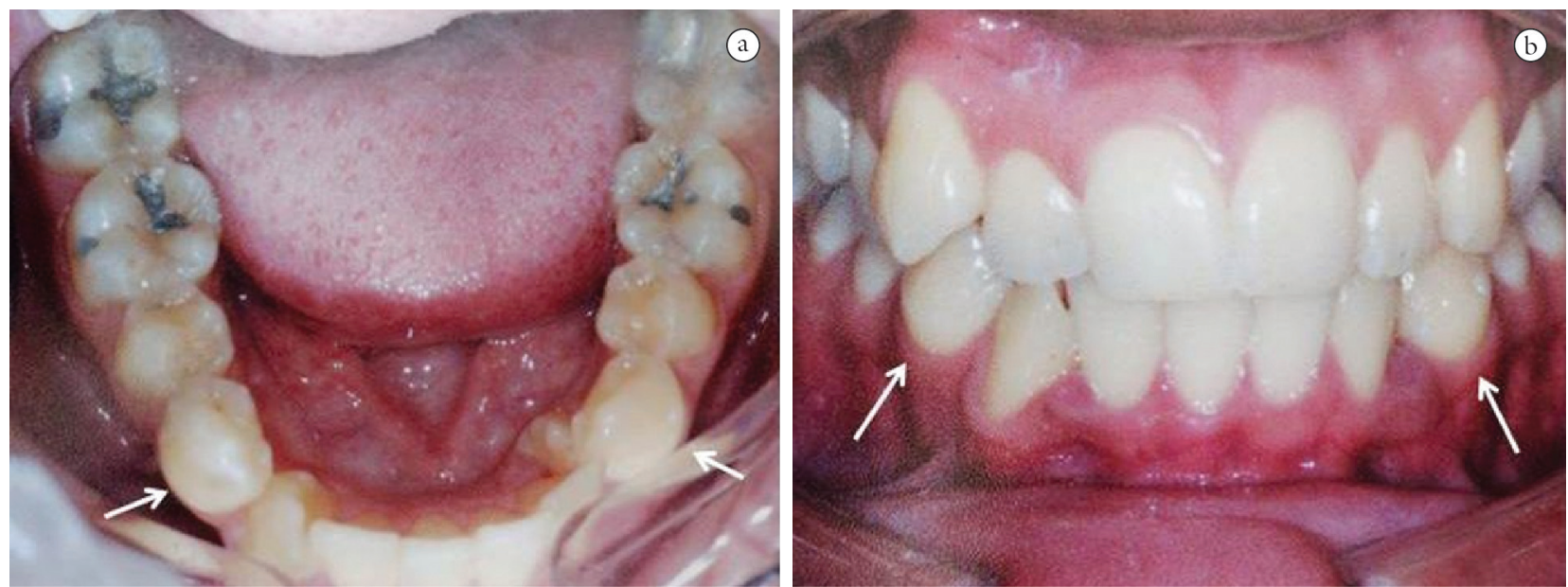

Figure 1. Clinical images. (A) Oclusal view of lower arch and (B) front view at maximum intercuspation, showing the tooth shape deviations (arrows).
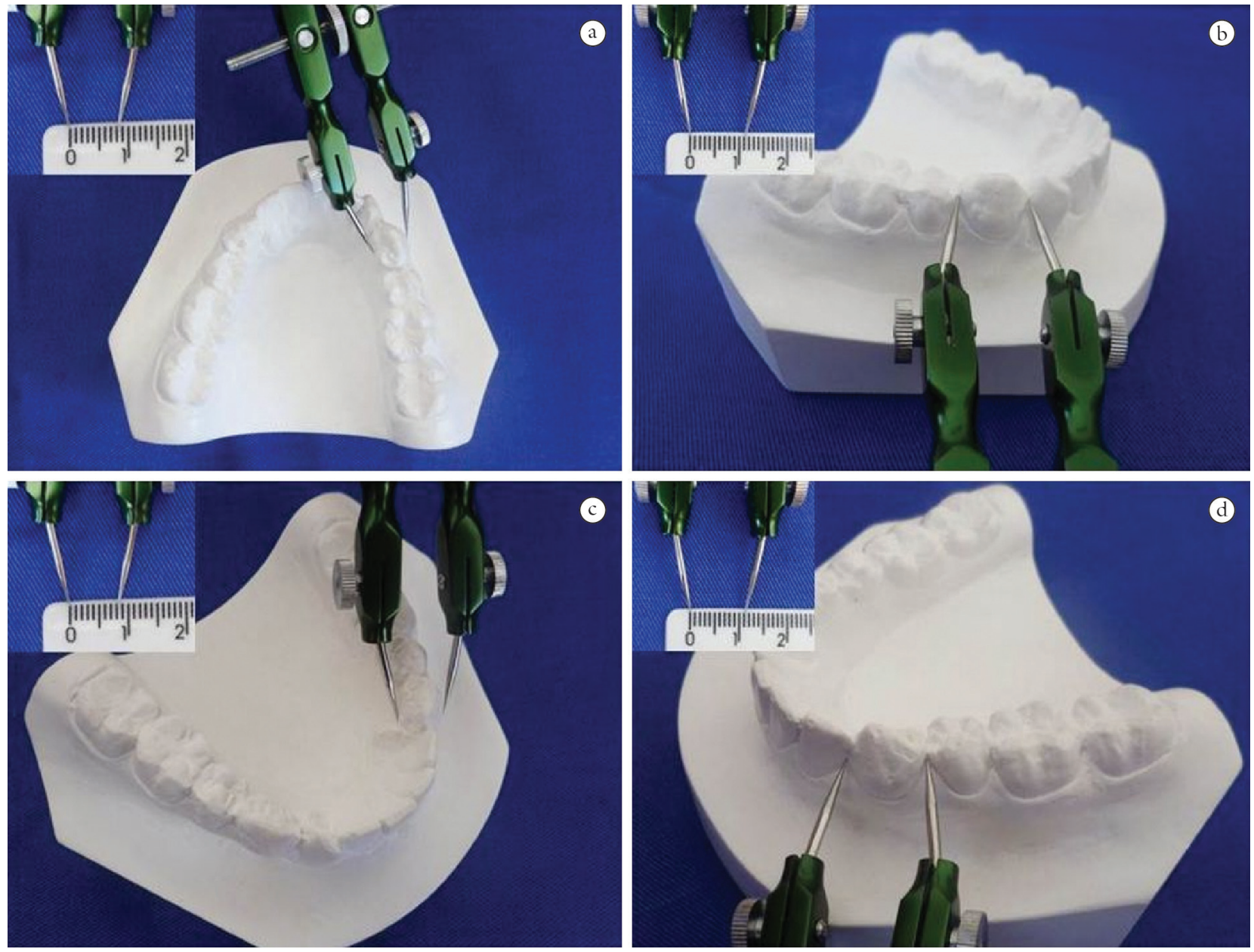

Figure 2. Study models of the lower arch. Measuring distances (A) bucco-lingual $(8 \mathrm{~mm})$ and $(\mathrm{B})$ mesio-distal (11 mm) of the right mandibular first premolar; and (C) bucco-lingual $(8 \mathrm{~mm})$ and $(\mathrm{D})$ mesio-distal $(1 \mathrm{~mm})$ of the left mandibular first premolar. 


\section{Discussion}

Teeth are susceptible to numerous developmental alterations, which may be primary, or arise secondarily due to environmental influences (GUPTA; SAXENA; JAIN et al., 2011; KAPDAN; KUSTARCI; BULDUR et al., 2012). There are various hypotheses about the origins of these abnormalities, such hereditariness, hyperactivity of the dental lamina, normal dental germ division, activity of dental lamina remnants and Hertwig sheath, lack of space for normal eruption and nutritional deficiencies. In addition, genetic mutations due to interaction with environmental factors, traumatism, local infection and radiation may also be associated with dental developmental anomalies (GARIB, ZANELLA and PECK, 2005).

These developmental anomalies may manifest as simple alterations in shape or position of the teeth, or appear as alterations that are so complex that lead to structural disorganization of the enamel and dentin (MIZIARA; MENDES-JUNIOR; WIEZEL et al., 2008). During the mixed dentition stage, one may foresee the patient being affected by problems caused by dental anomalies (KAPDAN; KUSTARCI; BULDUR et al., 2012). For this, the panoramic radiograph is an esential complementary exam, which have been shown to be an efficient tool for the evaluation of dental anomalies, as has been revealed in several studies (GUPTA; SAXENA; JAIN et al., 2011; KAPDAN; KUSTARCI; BULDUR et al., 2012; MIZIARA; MENDES-JUNIOR; WIEZEL et al., 2008).

The maxillary third molars, maxillary lateral incisors and mandibular premolars are the teeth most frequently affected by anomalies. There are more reports of involvement of the mandibular premolars with anomalies in number and position, and only some reports of their change in size or shape (GARIB and PECK, 2006). Regarding to the alterations in size and shape, cases of tooth shape deviation are also included, as well as alteration in the size of premolars, in which the mesio-distal dimension is exaggeratedly increased and the bucco-lingual dimension diminished simultaneously (GARIB and PECK, 2006), when compared with teeth of normal size (CABRERA; PINZAN; CABRERA et al., 2011). The size values of normal teeth are shown in Table 1. In the present case, although the affected teeth presented a discreetly diminished bucco-lingual dimension, they could be considered tooth shape deviations.

The presence of malocclusion in patients that seek orthodontic treatment is frequently associated with dental anomalies, as occurred in the present case. Nevertheless, tooth shape deviation has shown little prevalence when compared with other forms of dental anomalies (USLU; AKCAM; EVIRGEN et al., 2009). The bilateral occurrence of tooth shape deviation in the mandibular first premolars is rare (Table 2).

Knowledge of this anatomic variation has a great influence on establishing the orthodontic treatment plan of patients, since it causes the development of malocclusions (GARIB, ZANELLA and PECK, 2005), as was seen in the case here reported, in which the tooth shape deviations altered the arch perimeter, leading to retention of the mandibular permanent canine and presence of tooth crowding. In addition to malocclusions, the anomalies of shape and size predispose the affected tooth to caries, since there is greater irregularity of its occlusal surface (DADPE, KALE and PATIL, 2010).

Table 1. Mean values in millimeters of mesio-distal and bucco-lingual dimensions of premolars of the normal upper and lower arches in males and females*.

\begin{tabular}{ccccc}
\hline & \multicolumn{3}{c}{ Maxillary Arch } \\
\hline \multirow{2}{*}{ Teeth } & \multicolumn{3}{c}{ Male } & \multicolumn{2}{c}{ Female } \\
\cline { 2 - 5 } & Mesio-distal & Bucco-lingual & Mesio-distal & Bucco-lingual \\
\hline 4 & 7.28 & 9.60 & 7.06 & 9.46 \\
5 & 7.10 & 9.82 & 6.82 & 9.58 \\
\hline Teeth & \multicolumn{2}{c}{ Mandibular Arch } & Female \\
\hline & Mesio-distal & Bucco-lingual & Mesio-distal & Bucco-lingual \\
\hline 4 & 7.50 & 8.20 & 7.13 & 7.76 \\
5 & 7.53 & 8.76 & 7.20 & 8.49 \\
\hline
\end{tabular}

*Data adapted from Cabrera et al. (2011).

Table 2. Studies reporting cases of tooth shape deviation in the first premolars bilaterally.

\begin{tabular}{|c|c|c|c|c|c|}
\hline Authors & $\mathbf{n}^{\dagger}$ & $\mathrm{MnPl}-\mathrm{R}+\mathrm{L}^{\ddagger}$ & Origin & Gender & $\mathrm{MD} / \mathrm{BL}^{\S}$ \\
\hline Peck and Peck (1975) & 2 & 1 & USA & Female & $\begin{array}{l}\text { MnPl-R*: } 122 \\
\text { MnPl-L: } 122\end{array}$ \\
\hline \multirow[t]{2}{*}{ Garib and Peck (2006) } & 19 & 2 & USA & Female & $\begin{array}{l}\text { MnPl-R: } 118,4 \\
\text { MnPl-L: } 124,1\end{array}$ \\
\hline & & & Brazil & Female & $\begin{array}{l}\text { MnPl-R: } 107,1 \\
\text { MnPl-L: } 105,6\end{array}$ \\
\hline Chate (2012) & 56 & $\begin{array}{l}5 \\
6\end{array}$ & $\begin{array}{l}\text { United Kingdom } \\
\text { United Kingdom }\end{array}$ & $\begin{array}{c}\text { Male } \\
\text { Female }\end{array}$ & $\begin{array}{l}\mathrm{MnP1}: 111,9 \\
\mathrm{MnP1}: 108,0\end{array}$ \\
\hline
\end{tabular}

${ }^{\dagger}$ Total study sample. $\ddagger$ Occurrence of tooth shape deviation in the right and left mandibular first premolars. ${ }^{\circledR} \mathrm{MD}-\mathrm{Mesio}$-distal/ BL - Bucco-lingual. *MnPl-R- Right mandibular first premolar; MnPl-L: Left mandibular first premolar. 


\section{Conclusion}

Tooth shape deviation consists of a dental anomaly of size and shape with low prevalence, which affects the mandibular first premolars. This anatomic variation may be involved in the cause of dental malocclusion, since the additional space required for its positioning in the dental arch may lead to an adverse effect on the alignment of the other teeth. Therefore, the dentist, particularly the orthodontist, must be capable of recognizing this anomaly and consider it during the orthodontic planning stage.

\section{References}

CABRERA, CAG., PINZAN, A., CABRERA, MC., HENRIQUES, JFC., JANSON, G. and FREITAS, MR. Biometric study of human teeth. Dental Press Journal Orthodontics, 2011, vol. 16, p. 111-122.

CANUT, JA. and ARIAS, S. Molarization of the lower second premolars. Angle Orthodontist, 1999, vol. 69, p. 380-381. PMid:10456607.

CHATE, RAC. Odontometric evaluation of mandibular premolars with tooth shape deviation - a case-control study. Angle Orthodontist, 2012, vol. 82, n. 5, p. 785-791. http://dx.doi. org/10.2319/110411-684.1

DADPE, MV., KALE, YJ. and PATIL, PS. Molarization of the mandibular second premolars with concurrent dentin dysplasia: A rare case report. International Journal of Contemporary Dentistry, 2010, vol. 1, p. 66-69.

DUGMORE, CR. Bilateral macrodontia of mandibular second premolars: a case report. International Journal of Paediatric Dentistry, 2001, vol. 11, p. 69-73. PMid:11309876. http://dx.doi. org/10.1046/j.1365-263x.2001.00215.x

FUENTES, R. and BORIE, E. Bilateral macrodontia of mandibular second premolars: a case report. Journal of Morphological Science, 2011, vol. 28, p. 212-215.
GARIB, DG. and PECK, S. Extreme variations in the shape of mandibular premolars. American Journal of Orthodontic and Dentofacial Orthopedics, 2006, vol. 130, p. 317323. PMid:16979489. http://dx.doi.org/10.1016/j. ajodo.2005.01.022

GARIB, DG., ZANELLA, NLM. and PECK, S. Associated dental anomalies: case report. Journal of Applied Oral Science, 2005, vol. 13, p. 431-436. PMid:20865232.

GUPTA, SK., SAXENA, P., JAIN, S. and JAIN, D. Prevalence and distribution of selected developmental dental anomalies in an Indian population. Journal of Oral Science, 2011, vol. 53, p. 231-238. PMid:21712629. http://dx.doi.org/10.2334/josnusd.53.231

KAPDAN, A., KUSTARCI, A., BULDUR, B., ARSLAN, D. and KAPDAN, A. Dental anomalies in the primary dentition of Turkish children. European Journal of Dentistry, 2012, vol. 6, p. 178-183. PMid:22509121 PMCid:PMC3327494.

MIZIARA, RC., MENDES-JUNIOR, CT., WIEZEL, CEV., SIMÕES, AL., SCUOTEGUAZZA, JAC. and AZOUBEL, R. A Statistical Study of the Association of Seven Dental Anomalies in the Brazilian Population. International Journal of Morphology, 2008, vol. 26, p. 403-406.

NAGPAL, A., PAI, KM. and SHARMA, G. Palatal and labially impacted maxillary canine-associated dental anomalies: a comparative study. Journal of Contemporary Dental Practice, 2009, vol. 10, p. 67-74. PMid:19575056.

PECK, S. and PECK, H. Orthodontic Aspects of Dental Anthropology. Indian Journal of Dental Advancements, 1975 , vol. 45 , p. $95-102$.

USLU, O., AKCAM, MO., EVIRGEN, S. and CEBECI, I. Prevalence of dental anomalies in various malocclusions. American Journal of Orthodontics and Dentofacial Orthopedics, 2009, vol. 135, p. 328-335. PMid:19268831. http://dx.doi.org/10.1016/j. ajodo.2007.03.030 